\title{
Terrestrosin D, a Steroidal Saponin from Tribulus terrestris L., Inhibits Growth and Angiogenesis of Human Prostate Cancer in vitro and in vivo
}

\author{
Shihu Wei ${ }^{a}$ Hideo Fukuhara ${ }^{a}$ Guang Chen ${ }^{c}$ Chiaki Kawada $^{a}$ \\ Atsushi Kurabayashi $^{\text {b }}$ Mutsuo Furihata $^{b}$ Keiji Inoue $^{a}$ Taro Shuin $^{a}$ \\ Departments of a Urology and ${ }^{b}$ Pathology, Kochi Medical School, Nankoku, Japan; ${ }^{c}$ College of Life Science and \\ Technology, Beijing University of Chemical Technology, Beijing, PR China
}

\section{Key Words}

Terrestrosin D · Steroidal saponin · Apoptosis .

Angiogenesis

\begin{abstract}
Objective: The aim of this study was to investigate whether terrestrosin D (TED) inhibits the progression of castrationresistant prostate cancer and consider its mechanism. Methods: Cell cycle, mitochondrial membrane potential $(\Delta \Psi \mathrm{m})$ and apoptosis were determined by flow cytometry. Caspase-3 activity and vascular endothelial growth factor secretion were detected by a caspase- 3 assay and human vascular endothelial growth factor kit, respectively. A PC-3 xenograft mouse model was used to evaluate the anticancer effect of TED in vivo. Results: In vitro, TED strongly suppressed the growth of prostate cancer cells and endothelial cells in a dose-dependent manner. TED induced cell cycle arrest and apoptosis in PC-3 cells and human umbilical vascular endothelial cells (HUVECs). TED-induced apoptosis did not involve the caspase pathway. TED also decreased $\Delta \Psi_{\mathrm{m}}$ in PC-3 cells and HUVECs. In vivo, TED significantly suppressed tumor growth in nude mice bearing PC-3 cells, without any
\end{abstract}

\section{KARGER}

E-Mail karger@karger.com www.karger.com/pat overt toxicity. Immunohistochemical analysis showed TED induced apoptotic cell death and inhibited angiogenesis in xenograft tumor cells. Conclusion: Cell cycle arrest and induction of apoptosis in cancer cells and endothelial cells might be plausible mechanisms of actions for the observed antitumor and antiangiogenic activities of TED.

(c) 2014 S. Karger AG, Basel

\section{Introduction}

Prostate cancer (PCa) is the most frequently diagnosed cancer and the second leading cause of cancer-related death in American males [1]. Androgen ablation therapy is an effective treatment during the early stages of $\mathrm{PCa}$; however, it is associated with several side effects including loss of libido and bone density as well as cardiovascular morbidity [2]. Moreover, most PCa ultimately progresses to metastatic castration-resistant PCa (CRPC) after hormone therapy [3-5]. Although clinical trial data have shown that enzalutamide and abiraterone acetate significantly prolong overall survival in patients with metastatic CRPC, there is currently no systemic and effective ther- (c) 2014 S. Karger AG, Basel

1015-2008/14/0813-0123\$39.50/0 
apy for CRPC [5-7]. As available treatment options for CRPC is lacking, there is a growing need to develop novel therapeutic approaches against this fatal disease.

Tribulus terrestris L., a medicinal plant distributed widely in Mediterranean, subtropical and desert climates worldwide, has been used since ancient times as an aphrodisiac as well as to treat urinary infections, inflammation and cancer $[8,9]$. Recent studies have shown that $T$. terrestris extracts induce cell growth arrest and apoptosis by downregulating NF- $\kappa \mathrm{B}$ signaling in liver cancer cells, and that it exhibits weak cytotoxic effects to normal cells compared to cancer cells $[9,10]$. The observed biological activities of T. terrestris are mainly due to its abundant steroidal saponins [10-13]. Researchers have focused on steroidal saponins as potential candidates for the development of chemotherapeutic agents due to their anticancer effects [14-16]. However, the potential anticancer effects of terrestrosin D (TED; fig. 1), a major steroidal saponin of T. terrestris, remain unknown. Considering that the mechanism of anticancer effect of $T$. terrestris remains largely unknown and TED is the main constituent of T. terrestris, we studied the antitumor activity of TED and considered its mechanisms.

Cancer cells overexpress antiapoptotic regulators to limit or circumvent apoptosis, ultimately leading to uncontrolled proliferation [17]. Therefore, inducing apoptosis in tumor cells might be a feasible strategy to suppress tumor growth. During tumor progression, an 'angiogenic switch' is almost always activated and remains on, causing sustained angiogenesis that help neoplastic growths, invasion and metastasis $[17,18]$, which suggests angiogenic pathway inhibition is an alternative to inhibit cancer proliferation. This study is the first to describe that TED exhibits antitumor and antiangiogenic potential through induction of apoptosis and cell cycle arrest in $\mathrm{PCa}$ and endothelial cells in vitro, and that it is effective in a PC-3 cell-bearing nude mouse xenograft model.

\section{Materials and Methods}

\section{Cell Lines and Culture Conditions}

PC-3, PC-3M, DU145 and LNCaP cells were grown as a monolayer in Dulbecco's modified Eagle's medium (DMEM) supplemented with $10 \%$ fetal bovine serum (FBS). 22RV1 cells were cultured in RPMI 1640 medium supplemented with 10\% FBS. Human umbilical vascular endothelial cells (HUVECs) were maintained in EBM-2 supplemented with 2\% FBS and growth supplements (EGM-2 kit; Clonetics, San Diego, Calif., USA). Bladder-derived normal human microvascular endothelial cells were grown as a monolayer in EBM-2 supplemented with 2\% FBS and growth supplements (EGM-2 MV kit). These cells were incubated at $37^{\circ} \mathrm{C}$ in a $5 \% \mathrm{CO}_{2}$ environment.

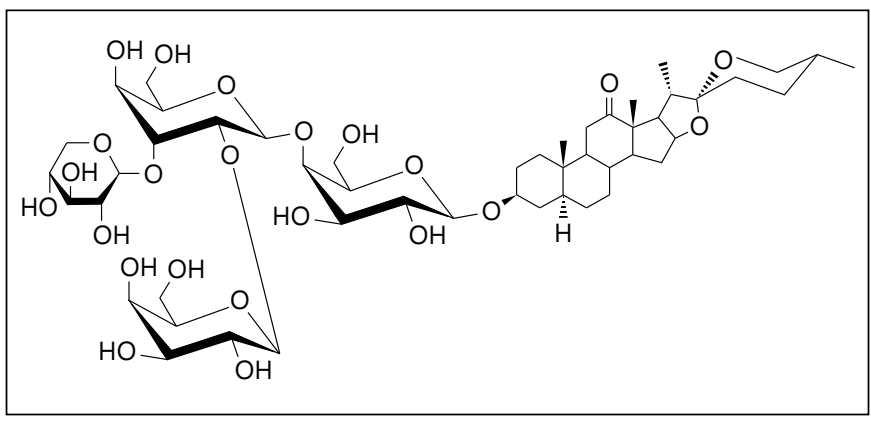

Fig. 1. Structure of TED.

\section{Chemicals}

TED was isolated from T. terrestris as described previously [19]. For in vitro assay, stock solutions (50 mM) were prepared in DMSO. The purity of TED was $>97 \%$ detected by HPLC. The working solution was prepared by diluting the stock solution with medium. For in vivo study, TED was suspended in saline.

\section{Cell Viability Assay}

Cells were seeded in 96-well microtiter plates for $24 \mathrm{~h}$ for adhesion before drug treatment, then the medium containing the various concentrations of TED was added. After 24-hour exposure to the drug, 3-(4,5-dimethyl-thiogol-2-yl)-2,5-diplenyltetrazollium (MTT) was added to each well and incubated for $3 \mathrm{~h}$ to allow the mitochondria dehydrogenase to covert MTT into an insoluble formazan product. The medium was then aspirated and the sediment was dissolved in DMSO. Absorbance was detected at $570 \mathrm{~nm}$ for cell viability.

\section{Flow Cytometry Analysis}

After treatment, the cells were trypsinized and washed with PBS. The samples were stained with propidium iodide (PI; $50 \mathrm{mg} /$ $\mathrm{ml}$ ), annexin $\mathrm{V}$ and PI, and tetramethylrhodamine methyl ester $(50 \mathrm{nM})$, and then analyzed by FACScan flow cytometry (Becton Dickinson) for cell cycle distribution, apoptosis and mitochondrial membrane potential $(\Delta \Psi \mathrm{m})$ assay, respectively. Data analysis was performed with ModFIT software [20].

\section{Caspase-3 Activity Assay}

Caspase- 3 activity was determined as described previously [21]. The cells were harvested and the lysates were prepared after treatment with TED. The lysates were then mixed with reaction buffer containing $20 \mathrm{mM}$ HEPES buffer ( $\mathrm{pH} 7.5$ ), $0.1 \mathrm{M} \mathrm{NaCl}$ and $10 \mu \mathrm{M}$ of Ac-DEVD-MCA as a substrate. Fluorescence of released 7-amino-4-methylcoumarin was measured using a fluorescence spectrophotometer with the excitation and emission wavelengths of 355 and $460 \mathrm{~nm}$, respectively.

\section{Quantification of Vascular Endothelial Growth Factor}

\section{Secretion}

Vascular endothelial growth factor (VEGF) secretion was determined as described by the manufacturer's introduction using a quantitative ELISA. The cells were seeded in 96-well plates. After treatment with various concentrations of TED, the cells were washed with PBS and fresh medium were added to each well. 
Twenty-four hours later, VEGF in culture supernatants were measured. The protein concentration was then determined by comparing the absorbance with that of a standard. Results were expressed in terms of cell numbers [18].

\section{In vivo Tumor Xenograft Study}

Male nude mice ( 5 weeks of age, BALB/c) were purchased from Clea Japan Inc. (Osaka, Japan). All animal experiments and care were conducted in a manner conforming to the Guidelines of the Animals Care and Use Committee of Kochi Medical School. PC-3 cells were injected subcutaneously into the flasks of the mice $(2 \times$ $10^{6}$ cells in $100 \mu \mathrm{l}$ of medium). To study nonestablished tumors, the treatment was initiated after tumor implantation. TED ( 25 or $50 \mathrm{mg} / \mathrm{kg}$ body weight) in $100 \mu \mathrm{l}$ of saline was administrated intraperitoneally 3 times a week for 4 weeks. The control group was treated with an equal volume of saline. Tumor volume was monitored using calipers and established according to the following formula: tumor volume $\left(\mathrm{mm}^{3}\right)=\pi \mathrm{ab}^{2} / 6$, where ' $\mathrm{a}$ ' is the length and ' $b$ ' is the width [22].

\section{Histology and Immunohistochemistry}

At the end of treatment, the mice were euthanized by cervical dislocation. Tumor tissue was withdrawn and fixed in $10 \%$ buffered formalin for 2 days at room temperature. Each clutch was processed into paraffin and cut into $10-\mu \mathrm{m}$ thick sections. The slide was then stained with hematoxylin and eosin using standard protocols [23]. Histological changes were examined using light microscopy. Proliferation and apoptosis of cancer cells were determined using immunohistochemistry with antibody for single-stranded DNA (Enzo Life Sciences Inc., Tokyo, Japan). Positive cells were counted as the average of the 5 highest areas identified within a single $400 \times$ field. The apoptosis index was according to the following formula: apoptosis index = apoptotic cells/1,000 cells. Microvessel density was determined by a light microscope after immunostaining of the sections with antiCD31 antibodies (Pharmingen, San Diego, Calif., USA) and expressed as the average of the 5 highest areas identified within a single $400 \times$ field [18].

\section{Statistics}

The changes between individual treatments of cells were analyzed with Student's test. Statistical significance in tumor subgroups was assessed by a Mann-Whitney test.

\section{Results}

\section{TED Results in Cell Cycle Arrest and Growth}

\section{Inhibition in PC-3 Cells and HUVECs}

To investigate the anticancer activity of TED, we first assessed its repression on the growth of 3 androgen-independent PCa cells (PC-3, PC-3M and DU145) and 2 androgen-dependent $\mathrm{PCa}$ cells (LNCaP and 22RV1). As shown in figure $2 \mathrm{a}$, treatment with TED for $24 \mathrm{~h}$ induced a dose-dependent decrease in cell viability compared with nontreated cells. The $\mathrm{IC}_{50}$ on these PCa cells was below $5 \mu \mathrm{M}$. These results show that TED can dramatically in- hibit the growth of PCa cells. For studying the effect of TED on CRPC, we used PC-3 cells in the following steps because they do not express androgen receptors and their growth is not dependent on androgen. Since we observed a strong growth inhibitory effect of TED in PC-3 cells, we next analyzed its possible inhibitory effect on cell cycle progression. PI staining flow cytometry analysis revealed that treatment with $5 \mu \mathrm{M}$ TED for $24 \mathrm{~h}$ caused significant increases in $G_{1}$ populations and concomitant decreases in $S$ phase populations. Representative flow cytometric curves are shown in figure $2 \mathrm{~b}$, and a compilation of the results is depicted in figure $2 \mathrm{c}$. Taken together, these results indicate that TED induced cell cycle arrest in the $G_{1}$ phase and inhibited the growth of PC-3 cells.

To access the antiangiogenic property of TED in vitro, we firstly examined its inhibitory effect on the viability of 2 endothelial cells, HUVECs and bladder-derived normal human microvascular endothelial cells. Endothelial cells were treated with increasing concentrations of TED for $24 \mathrm{~h}$. TED exhibited potential growth inhibition of endothelial cells in a dose-dependent manner. The $\mathrm{IC}_{50}$ on these 2 endothelial cells was below $3 \mu \mathrm{M}$ (fig. $2 \mathrm{~d}$ ). PI staining revealed that TED induced an $S$ arrest in HUVECs (fig. 2e, f). These results suggested TED induced cell cycle arrest in the $S$ phase and inhibited the growth of HUVECs.

\section{TED Induces Apoptosis in PC-3 Cells and HUVECs}

As TED treatment was found to exert cytotoxic effects on human cancer and endothelial cell lines, we investigated whether TED induced apoptotic cell death using annexin V-PI staining. Flow cytometry analysis indicated that treatment with TED for $24 \mathrm{~h}$ induced apoptosis in a dose-dependent manner in PC-3 cells (fig. 3a, b). Only $2.4 \%$ of the control cells were apoptotic, as compared to 6.1 and $60.5 \%$ of the cells that were treated with 2 and $5 \mu \mathrm{M}$ of TED, respectively. To identify whether or not TED-induced apoptosis involved the caspase pathway, PC- 3 cells were treated with TED at a dose of $5 \mu \mathrm{M}$ and incubated for $24 \mathrm{~h}$ after a $1 \mathrm{~h}$ treatment with $50 \mu \mathrm{M}$ of the caspase inhibitor $\mathrm{z}-\mathrm{VAD}$. The number of apoptotic cells induced by TED was not decreased by $z-V A D$ as compared to the cells not treated with $\mathrm{z}$-VAD (fig. 3c). The caspase inhibitor did not reverse TED-induced decreases in cell viability (data not shown). Additionally, analysis of the activity of caspase-3, a major effector caspase involved in caspase-dependent apoptosis, did not show any increase after treatment (fig. 3d). Taken together, TED induced apoptotic cell death in a caspase-independent manner in PC-3 cells. 


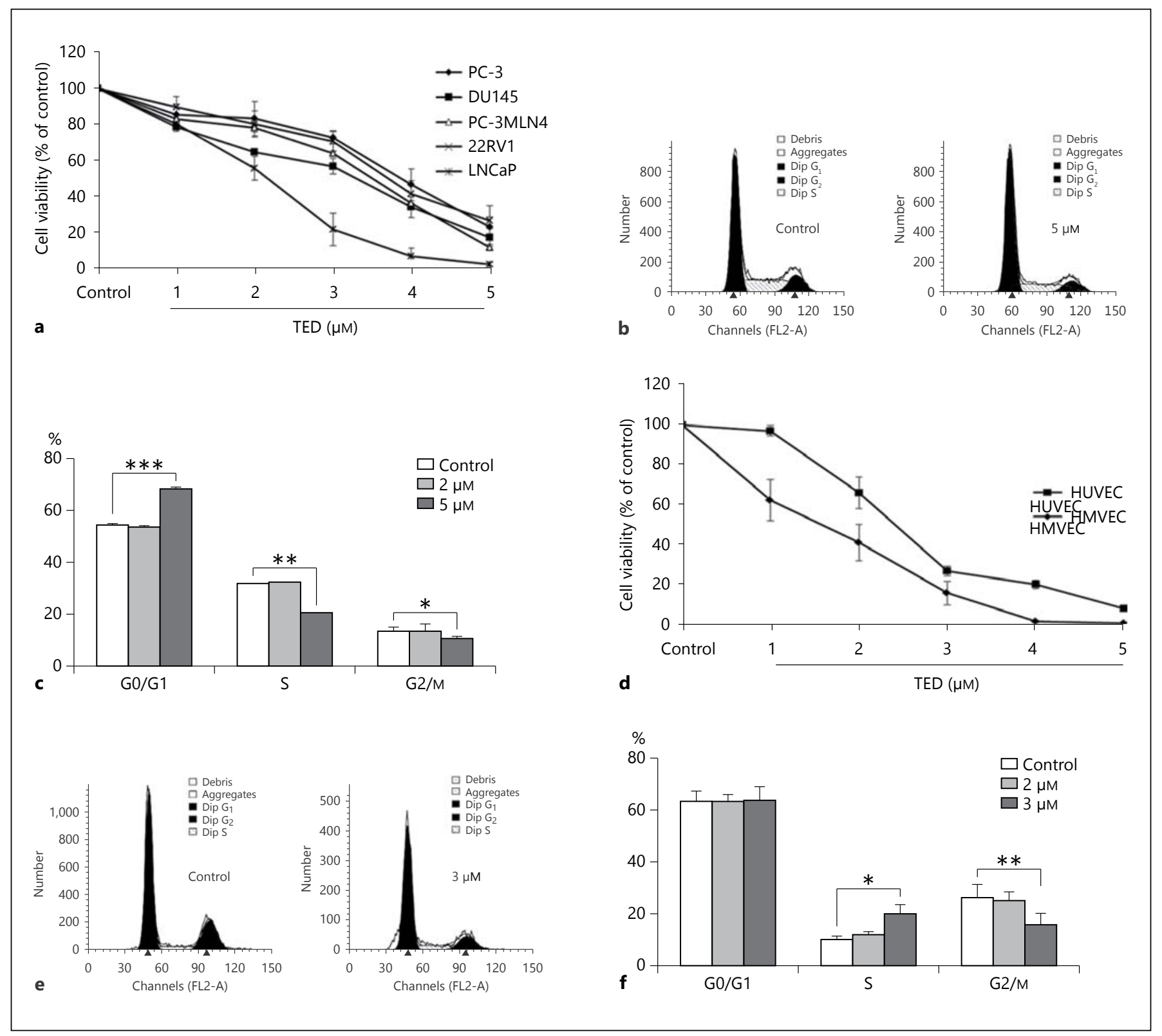

Fig. 2. Effects of TED on cell growth in human PCa cells and endothelial cells. TED decreased cell viability in PCa cell lines (a) and endothelial cell lines $(\mathbf{d})$. TED caused the $\mathrm{G}_{1}$ arrest in PC-3 cells $(\mathbf{b}, \mathbf{c})$ and the $\mathrm{S}$ arrest in HUVECs $(\mathbf{e}, \mathbf{f})$. Results are expressed as means \pm $\mathrm{SD}(\mathrm{n} \geq 3) .^{*} \mathrm{p}<0.05 ;^{* *} \mathrm{p}<0.01 ;{ }^{* * *} \mathrm{p}<0.005$ vs. control.

As shown in figure $3 \mathrm{f}, 5.9 \%$ of the control cells in the HUVECs were apoptotic. Treatment with 2 and $3 \mu \mathrm{M}$ of TED of induced 9.1 and $34.3 \%$ cells in apoptotic cell death, respectively. Thus, the result suggested that TED induced apoptosis in a dose-dependent manner in HUVECs. The lack of an effect of z-VAD on TED-induced apoptosis and reduced caspase- 3 activity indicated TED induced caspaseindependent apoptotic cell death in HUVECs (fig. 3g, h).

\section{TED Decreases $\triangle \Psi m$ in PC-3 Cells and HUVECs}

Since the distribution of $\Delta \Psi \mathrm{m}$ is an early but crucial process in cell death, we tried to evaluate whether TED induces depolarization of $\Delta \Psi \mathrm{m}$ in PC-3 cells and HUVECs. As shown in figure $4 \mathrm{a}$ and $\mathrm{b}$, treatment with $5 \mu \mathrm{M}$ of TED induced depolarization of $\Delta \Psi \mathrm{m}$ in $53.8 \%$ of the PC-3 cells as compared to $12.3 \%$ of the cells in the control group. However, a lower dose of TED $(2 \mu \mathrm{M})$ did 


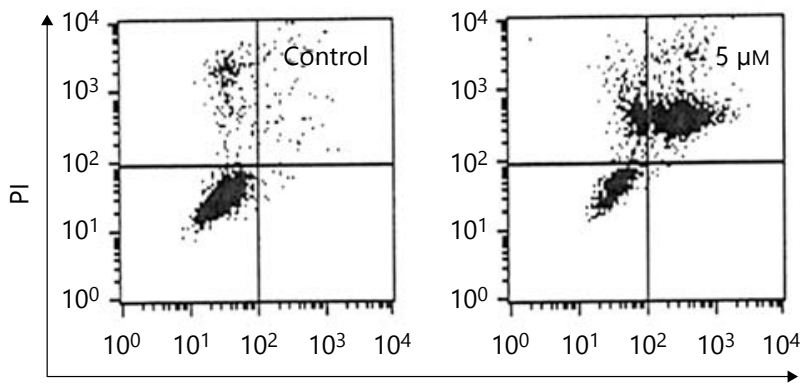

a

Annexin V FITC
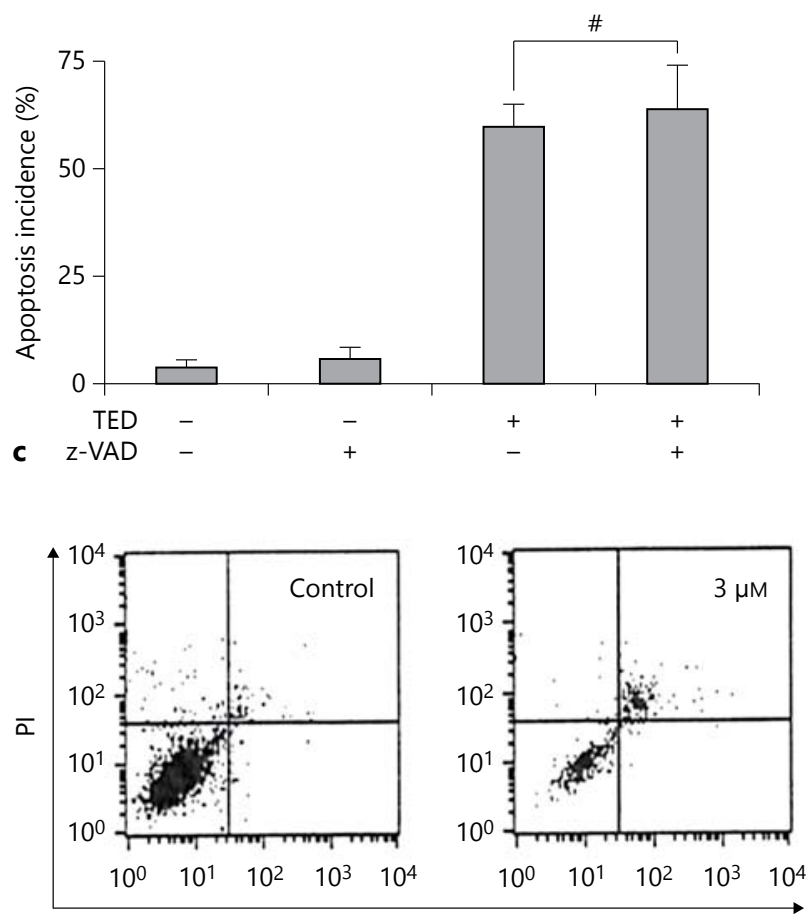

Annexin V FITC

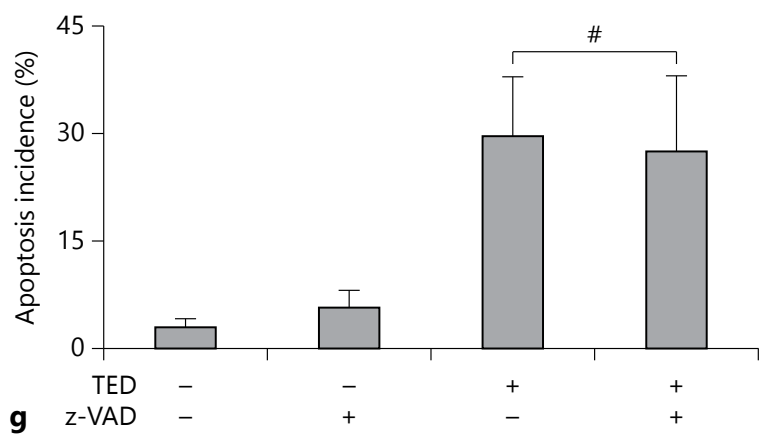

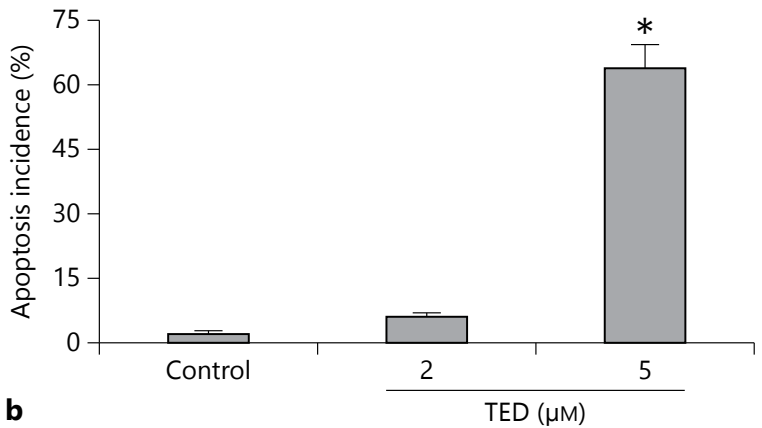
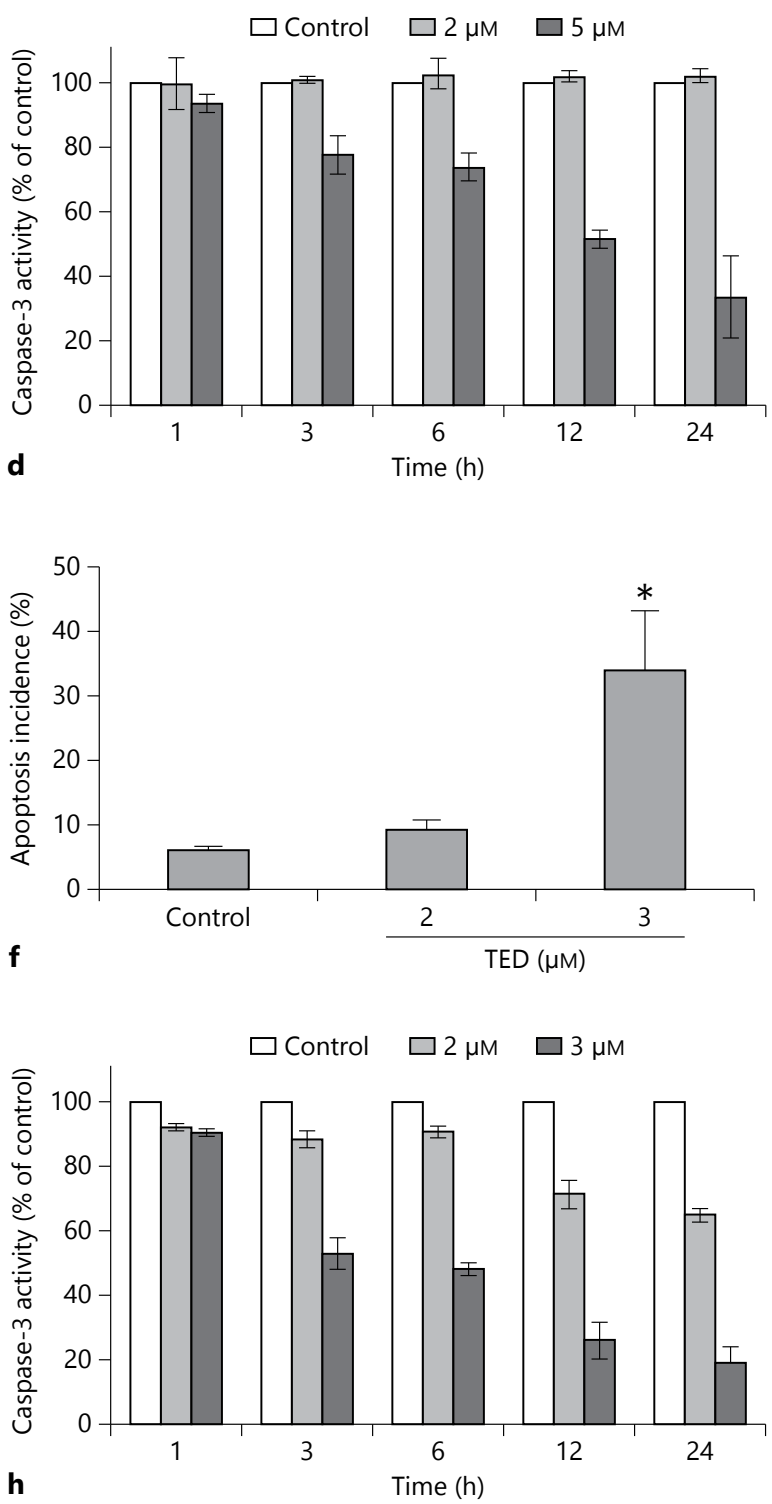

Fig. 3. Effects of TED on apoptosis in PC-3 cells and HUVECs. TED induced apoptosis in PC-3 cells (a, b) and HUVECs (e, f). z-VAD did not reverse TED-induced apoptosis in PC-3 cells (c) or HUVECs $(\mathbf{g})$. The activity of caspase-3 was reduced by TED in PC-3 cells (d) and HUVECs $(\mathbf{h})$. Results are expressed as means $\pm \mathrm{SD}(\mathrm{n}=3){ }^{*} \mathrm{p}<0.05$; ${ }^{*} \mathrm{p}>0.05$ vs. control. 

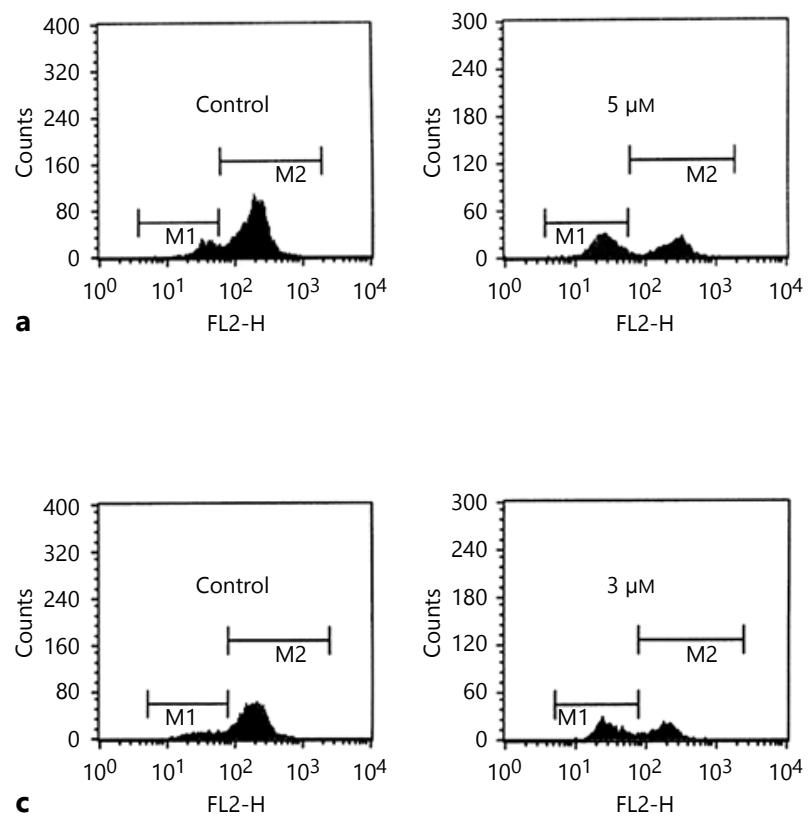

Fig. 4. Effects of TED on $\Delta \Psi \mathrm{m}$ in PC-3 cells and HUVECs. TED decreased the $\Delta \Psi \mathrm{m}$ in PC-3 cells (a, b) and HUVECs (c, d). M1 = Dead cells; M2 = alive cells. Results are expressed as means \pm SD $(n=3) .{ }^{*} \mathrm{p}<0.05 ;{ }^{* *} \mathrm{p}<0.01 ;{ }^{* * *} \mathrm{p}<0.005$ vs. control.

not induce depolarization of $\Delta \Psi \mathrm{m}$ as compared to the control group. Thus, TED induced depolarization of $\Delta \Psi \mathrm{m}$ in higher concentrations in PC-3 cells.

TMRE staining flow cytometric analysis indicated that $\Delta \Psi \mathrm{m}$ was depleted in a concentration-dependent manner after TED treatment for $24 \mathrm{~h}$ in HUVECs. Treatment with 2 and $3 \mu \mathrm{M}$ of TED induced depolarization of $\Delta \Psi \mathrm{m}$ in 28.8 and $57.3 \%$ of HUVECs, respectively, as compared to $13.5 \%$ of the cells in the control group (fig. $4 \mathrm{c}, \mathrm{d}$ ).

\section{TED Inhibits Tumor Growth in vivo}

Agents which are active in vitro may not be the same in vivo due to low bioavailability, a fast removal rate or failure in deliverance. To address this issue, we investigated the effect of TED on tumor growth in a mouse model of PCa. We found that administration of TED $(50 \mathrm{mg} /$ $\mathrm{kg}$ ) substantially suppressed tumor growth (fig. 5a, b). The average tumor volume in the control mice was $315.75 \pm 108.54 \mathrm{~mm}^{3}$ after 28 days, whereas the average tumor volume in the TED-treated mice was $127.41 \pm$ $51.65 \mathrm{~mm}^{3}$. However, the same dose of TED had no significant effect on the body weight of the mice (fig. 5c), suggesting low toxicity of TED at the test dosage and con-
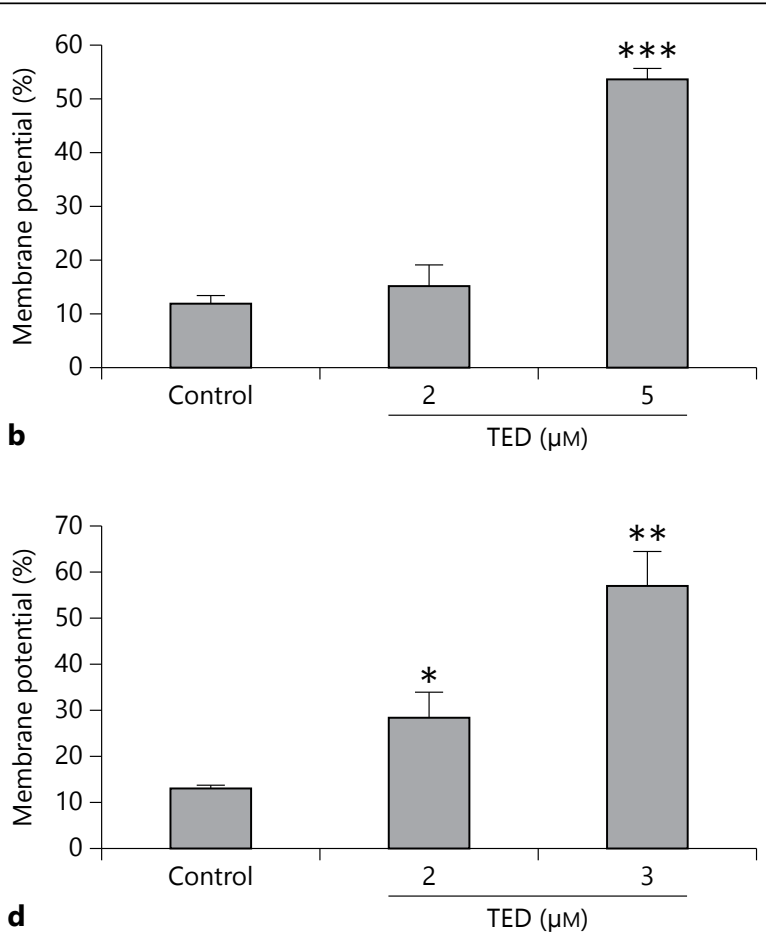

ditions. A lower dose of TED (25 mg/kg) had little effect on tumor growth (data not shown). Immunohistochemical analysis of tumors with single-stranded DNA showed that TED induced apoptotic death in xenograft tumor tissues. The apoptosis index in the control group was $32.4 \pm$ 6.3 compared with $58.5 \pm 8.1$ in the TED-treated groups (fig. $5 \mathrm{~d}$ ). These results suggested that TED inhibited tumor growth in vivo.

To investigate whether TED inhibited tumor growth through the inhibition of tumor angiogenesis, we used anti-CD31 antibody to stain solid tumor sections in the xenograft mouse model. As shown in figure $5 \mathrm{e}$, microvessel density counted per $400 \times$ field in the TED-treated group was $17.6 \pm 1.6$ compared with $31.5 \pm 5.8$ in the control group, indicating that TED significantly inhibited tumor angiogenesis.

\section{TED Increases VEGF Secretion in PC-3 Cells and HUVECS}

VEGF is one of the most potent angiogenic cytokines in the angiogenesis process. Since we observed a strong inhibitory effect of TED on angiogenesis in solid tumor sections, we next analyzed its possible inhibitory effect on 

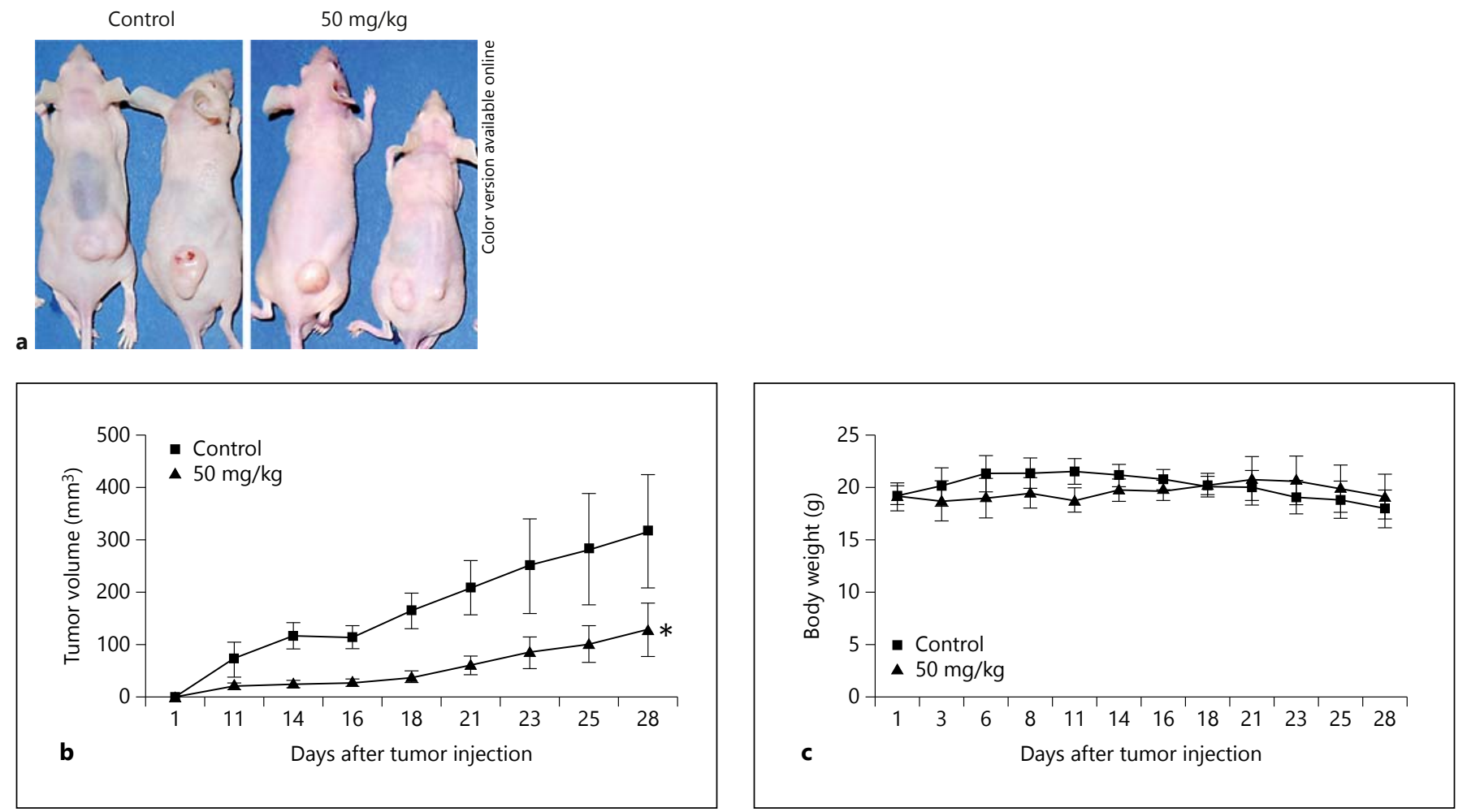

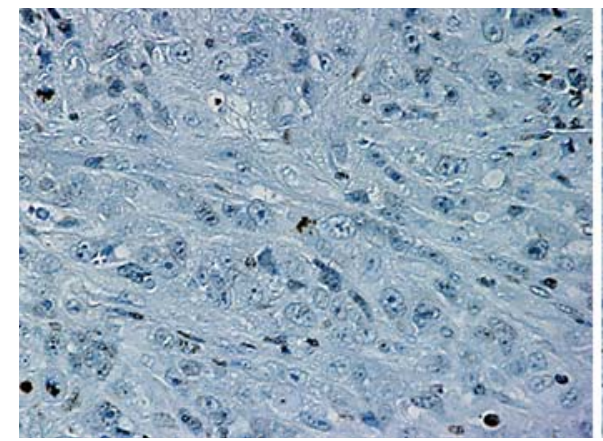

d

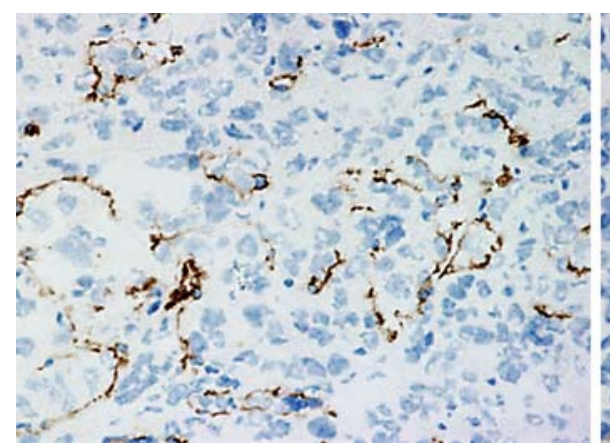

e

Control

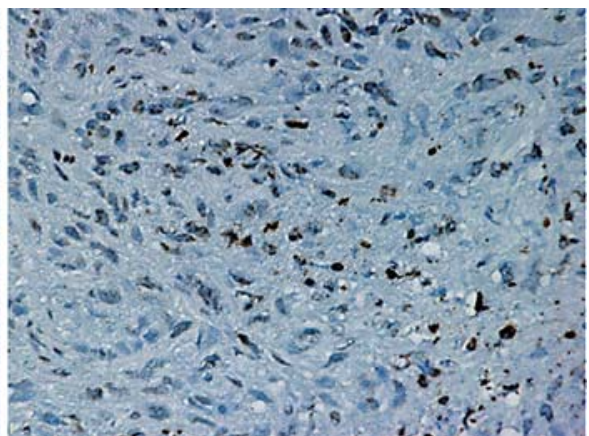

$50 \mathrm{mg} / \mathrm{kg}$
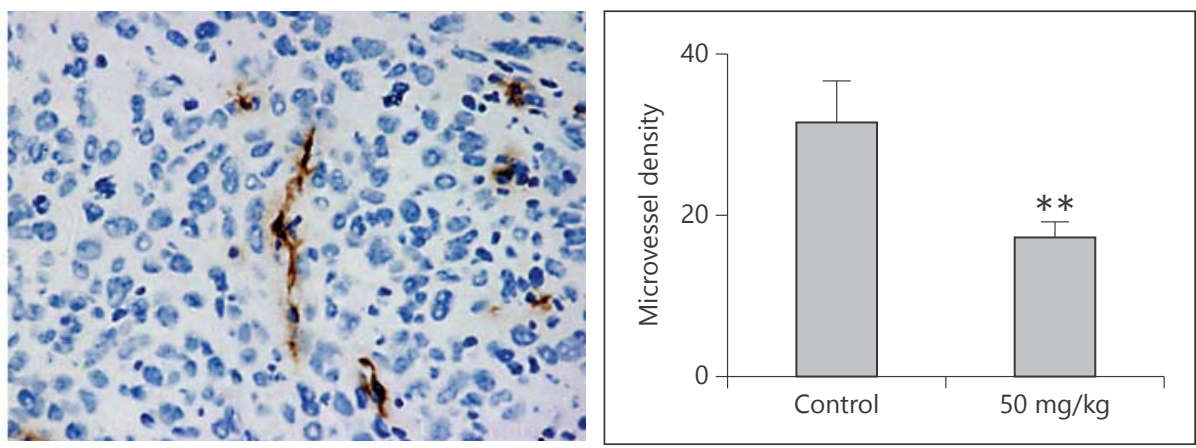

Fig. 5. Effects of TED on the tumor growth and angiogenesis in vivo. a, b TED inhibited tumor growth in a PC-3 xenograft mice model (each group, $\mathrm{n}=5$; $^{*} \mathrm{p}<0.05$ ). $\mathbf{c}$ TED did not change body weight of nude mice. $\mathbf{d}$ TED induced apoptosis in xenograft tumor tissues: left, immunohistochemistry for single-stranded DNA
(400×); right, bar graph showing apoptosis index. e TED inhibited microvessel formation: left, immunohistochemistry for CD31 (400×); right, bar graph showing microvessel density. Results are expressed as the average number of the 5 highest areas identified within a single $400 \times$ field; ${ }^{* *} \mathrm{p}<0.01$. 

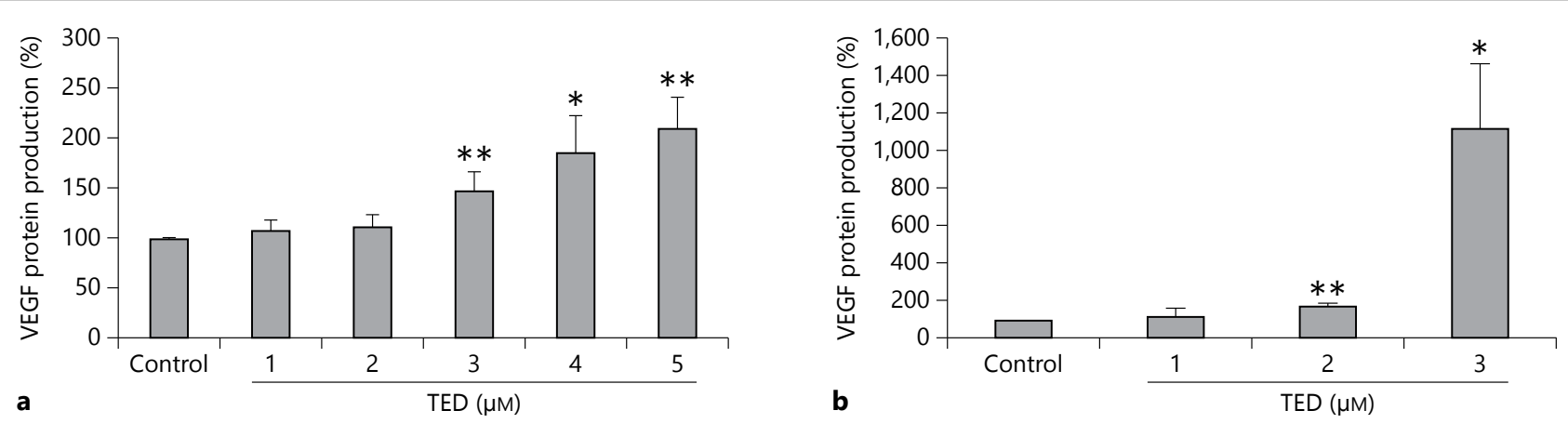

Fig. 6. Effects of TED on VEGF secretion and mRNA in PC-3 cells and HUVECs. TED increased VEGF secretion in PC-3 cells (a) and HUVECs (b). Results are expressed as means $\pm \mathrm{SD}(\mathrm{n}=3) .{ }^{*} \mathrm{p}<0.05 ;{ }^{* *} \mathrm{p}<0.01$ vs. control.

VEGF secretion. Contrary to our hypothesis, in vitro treatment with TED for $24 \mathrm{~h}$ increased VEGF secretion in a dose-dependent manner in PC-3 cells and HUVECs (fig. 6a, b). The ELISA analysis showed that treatment with $5 \mu \mathrm{M}$ TED resulted in a 1.86-fold increase of VEGF levels. At a dose of $3 \mu \mathrm{M}$, an 11.21-fold increase in VEGF secretion was observed in the HUVECs.

\section{Discussion}

PCa causes significant morbidity and mortality, and is a major public problem in America and Europe. Although androgen ablation therapy can prolong the life expectancy of patients, acquired drug resistance and the induction of side effects remains a major obstacle in clinical settings. Over the last few decades, attention has been focused on natural products as potential sources of novel anticancer drugs [24]. In this study, we elevated the effect of TED on the growth of human PCa. TED effectively targeted and inhibited the growth of PCa cells and endothelial cells, which led to the suppression of tumor growth and angiogenesis. This is the first report that characterizes the antitumor properties of TED and its mechanism in both cells and a tumor xenograft model.

Inhibiting cell growth is a critical action of anticancer drug-induced cancer death. In the present study, TED inhibited $20-90 \%$ of PCa cell growth using concentrations of $2-5 \mu \mathrm{M}$ (fig. 2a). Although the structure of TED is similar to androgens, which can stimulate androgen-dependent PCa cell growth, TED also decreased the cell viability of LNCaP and 22RV1 cells. Our results and other reports suggest that steroidal saponin has no effect on the androgen receptor [14]. The antiproliferative effect of
TED in PCa cells partly result from the $\mathrm{G}_{1}$ phase cell cycle arrest (fig. 2b, c).

Apoptosis, which contributes to cell growth inhibition in cancer cells, is another important strategy for overcoming cancer. TED induced apoptotic cell death in PC-3 cells (fig. 3a, b), which may be another cause of TED-induced cell growth inhibition. To study whether TED-induced apoptosis occurs through a caspase-dependent pathway, cells were treated with the caspase inhibitor zVAD before the addition of TED. $z$-VAD did not reverse TED-induced apoptotic cell death and decrease in cell viability (fig. 3c). We also found TED did not activate the activity of caspase-3, the main effector protease in the process of caspase-dependent apoptosis (fig. 3d). These results show that TED-induced apoptosis does not involve the caspase pathway.

Mitochondria serve as a core component of the cell death machinery. Attenuation of $\Delta \Psi \mathrm{m}$ from the mitochondrial intermembrane space triggers autophagy and/ or apoptosis. Some studies have shown that spirostanol saponin-induced mitochondrial membrane destabilization is due to their membrane perturbing property [25]. TED, one of the spirostanol saponins, disturbs mitochondrial membrane integrity so as to trigger PCa cell death.

For drug development, it is extremely important to evaluate the potency of the drug in vivo. To address this issue, we elevated the antitumor effect of TED in vivo in a mouse PC-3 xenograft model. The data suggest TED can effectively reduce the burden of PC-3 xenograft in a nude mouse model (fig. 5a, b). In our in vitro experiment, TED dramatically decreased cancer cell viability compared to other steroidal saponins reported in other groups $[15,26]$. At a relative higher dose, however, TED can inhibit tumor growth in vivo. This may be due to the low bioavailability 
of TED, which shows weak solubility in saline in our xenograft model. Although the mice were given a $50-\mathrm{mg} / \mathrm{kg}$ dose, no changes of weight, no differentiated behavior and no death, together with other groups' data, suggest TED has low toxicity (fig. 5c) [14, 26]. These results point to TED as a potential candidate for therapeutic use. For future studies and use, technologies that can improve TED and other steroidal saponin solubility as well as the metabolic pathways of TED should be elucidated.

Given the importance of tumor angiogenesis in the growth of $\mathrm{PCa}$, inhibition of the angiogenic pathway is an alternative to inhibit cancer proliferation. In this study, we first demonstrated that TED inhibited tumor growth through inhibition of tumor angiogenesis (fig. 5f). As some antiangiogenic agents show efficacy by targeting and inhibiting the growth of endothelial cells, the effect of TED on the growth of endothelial cells was studied. We assessed its repression on the growth of HUVECs and normal human microvascular endothelial cells (fig. 2d). This ability is due TED being able to induce $S$ phase cell cycle arrest and apoptosis (fig. $2 \mathrm{f}, 3 \mathrm{e}, \mathrm{f}$ ). These results suggest that the antiangiogenic property of TED is by targeting and inhibiting endothelial cells proliferation directly. As VEGF is a key regulator of angiogenesis, we then studied whether TED-inhibited angiogenesis involves decreasing its secretion. The data exhibited that TED did not decrease, but rather increased the secretion of VEGF in PC-3 cells and HUVECs (fig. 6a, b). Since VEGF is also a critical cell-specific survival factor, it may be secreted to protect the tumor vasculature during chemotherapy [27, 28]. Neutralization of secreted VEGF with anti-VEGF an- tibodies may enhance the antitumor activity of TED and other chemotherapies [8]. Taking these results together, the antiangiogenic ability of TED is achieved by targeting and inhibiting endothelial cells proliferation directly.

Like $T$. terrestris extracts, TED can inhibit cancer cell growth through the induction of cell cycle arrest and apoptosis [9]. Considering that TED is the main constituent of $T$. terrestris, TED may partly represent the pharmacological effects, especially the anticancer effect of $T$. terrestris. Our study also reveals that TED has an antiangiogenic property, which may suggest the anticancer effect of T. terrestris is also due to inhibition of tumor angiogenesis. In summary, our study reveals that TED inhibits the growth of PCa and endothelial cells by induction of cell cycle arrest and apoptosis, which leads to suppression of tumor growth and angiogenesis. Currently, maximal androgen blockade therapy is an effective treatment for PCa; however, it induces sexual dysfunction that troubles most patients, especially if they are young. TED treatment is a potential therapy for young patients to escape sexual dysfunction. We suggest TED treatment could be a firstline therapy for young patients who suffer PCa. Additional studies will focus on dissecting the mechanism of its action on the apoptotic pathway and antiangiogenesis in detail.

\section{Acknowledgements}

We thank Honorary Prof. Hiroyuki Kodama, Kochi Medical School, for his valuable professional assistance.

\section{References}

$>_{1}$ Siegel R, Naishadham D, Jemal A: Cancer statistics, 2012. CA Cancer J Clin 2012;62:10-29.

2 Volate SR, Kawasaki BT, Hurt EM, et al: Gossypol induces apoptosis by activating p53 in prostate cancer cells and prostate tumor-initiating cells. Mol Cancer Ther 2010;9:461-470.

3 Yoo JH, Kwon HC, Kim YJ, et al: KG-135, enriched with selected ginsenosides, inhibits the proliferation of human prostate cancer cells in culture and inhibits xenograft growth in athymic mice. Cancer Lett 2010;289:99-110.

4 Lin HP, Jiang SS, Chuu CP: Caffeic acid phenethyl ester causes p21 induction, Akt signaling reduction, and growth inhibition in PC-3 human prostate cancer cells. PLoS One 2012; 7:e31286

$\checkmark 5$ Fizazi K, Scher HI, Molina A, et al: Abiraterone acetate for treatment of metastatic castration-resistant prostate cancer: final overall survival analysis of the COU-AA-301 randomised, double-blind, placebo-controlled phase 3 study. Lancet Oncol 2012;13: 983-992.

6 6 Scher HI, Fizazi K, Saad F, et al: Increased survival with enzalutamide in prostate cancer after chemotherapy. N Engl J Med 2012;367: 1187-1197.

-7 Agarwal N, Sonpavde G, Sternberg CN: Novel molecular targets for the therapy of castration-resistant prostate cancer. Eur Urol 2012; 61:950-960.

-8 Martino-Andrade AJ, Morais RN, Spercoski KM, et al: Effects of Tribulus terrestris on endocrine sensitive organs in male and female Wistar rats. J Ethnopharmacol 2010;127:165-170.

9 $\mathrm{Kim}$ HJ, Kim JC, Min JS, et al: Aqueous extract of Tribulus terrestris Linn induces cell growth arrest and apoptosis by down-regulating NF- $\kappa \mathrm{B}$ signaling in liver cancer cells. J Ethnopharmacol 2011;136:197-203.
10 Neychev VK, Nikolova E, Zhelev N, et al: Saponins from Tribulus terrestris $\mathrm{L}$ are less toxic for normal human fibroblasts than for many cancer lines: influence on apoptosis and proliferation. Exp Biol Med 2011;232: 126-133.

11 Yan W, Ohtani K, Kasai R, et al: Steroidal saponins from fruits of Tribulus terrestris. Phytochemistry 1996;42:1417-1422.

-12 Su L, Chen G, Feng SG, et al: Steroidal saponins from Tribulus terrestris. Steroids 2009; 74:399-403.

13 Bedir E, Khan IA, Walker LA: Biologically active steroidal glycosides from Tribulus terrestris. Pharmazie 2002;57:491-493.

14 Lee MS, Yuet-Wa JC, Kong SK, et al: Effects of polyphyllin D, a steroidal saponin in Paris polyphylla, in growth inhibition of human breast cancer cells and in xenograft. Cancer Biol Ther 2005;4:1248-1254. 
15 Kang YJ, Chung HJ, Nam JW, Park HJ, et al: Cytotoxic and antineoplastic activity of timosaponin A-III for human colon cancer cells. J Nat Prod 2011;74:701-706.

16 Tong QY, Qing Y, Shu D, et al: Deltonin, a steroidal saponin, inhibits colon cancer cell growth in vitro and tumor growth in vivo via induction of apoptosis and antiangiogenesis. Cell Physiol Biochem 2011;27:233-242.

17 Hanahan D, Weinberg RA: Hallmarks of cancer: the next generation. Cell 2011;144:646674.

18 Inoue K, Chikazawa M, Fukata S, et al: Docetaxel enhances the therapeutic effect of the angiogenesis inhibitor TNP-470 (AGM-1470) in metastatic human transitional cell carcinoma. Clin Cancer Res 2003;9:886-899.

19 Wang RY, Cheng G, Yu CY: Chemical constituents of Tribulus terrestris L. Beijing Hua Gong Da Xue Xue Bao 2009;36:79-82.
20 Thakur VS, Gupta K, Gupta S: Green tea polyphenols causes cell cycle arrest and apoptosis in prostate cancer cells by suppressing class I histone deacetylases. Carcinogenesis 2012;33: 377-384.

21 Fujita H, Utsumi T, Muranaka S, et al: Involvement of Ras/extracellular signal-regulated kinase, but not Akt pathway in risedronate-induced apoptosis of U937 cells and its suppression by cytochalasin B. Biochem Pharmacol 2005;69:1773-1784.

22 Raj L, Ide T, Gurkar AU, et al: Selective killing of cancer cells by a small molecule targeting the stress response to ROS. Nature 2012;481: 485.

23 Lo EH, Ooi VE, Fung KP: Circumvention of multidrug resistance and reduction of cardiotoxicity of doxorubicin in vivo by coupling it with low density lipoprotein. Life Sci 2002;76: 677-687.

24 Hsiao WL, Liu L: The role of traditional Chinese herbal medicines in cancer therapy from TCM theory to mechanistic insights. Planta Med 2010;76:1118-1131.
25 Sy LK, Yan SC, Lok CN, et al: Timosaponin A-III induces autophagy preceding mitochondria-mediated apoptosis in HeLa cancer cells. Cancer Res 2008;68:10229-10237.

26 Hong SW, Jung KH, Lee HS, et al: SB365 inhibits angiogenesis and induces apoptosis of hepatocellular carcinoma through modulation of PI3K/Akt/mTOR signaling pathway. Cancer Sci 2012;103:1929-1937.

27 Wild R, Dings RP, Subramanian I, et al: Carboplatin selectively induces the VEGF stress response in endothelial cells: potentiation of antitumor activity by combination treatment with antibody to VEGF. Int J Cancer 2004; 110:343-351

28 Lev DC, Ruiz M, Mills L, et al: Dacarbazine causes transcriptional up-regulation of interleukin 8 and vascular endothelial growth factor in melanoma cells: a possible escape mechanism from chemotherapy. Mol Cancer Ther 2003;2:753-763. 